\title{
Desenvolvimento da ferrita delta na solda e ZTA resultante de soldagem plasma pulsada em um aço inoxidável supermartensítico
}

\section{(Delta-ferrite development in weld and HAZ produced by pulsed plasma arc welding in a supermartensitic stainless steel)}

\author{
Sérgio L. Henkel, Ramon S. C. Paredes ${ }^{1}$, André R. Capra². \\ ${ }^{1}$ Universidade Federal do Paraná, Departamento de Engenharia Mecânica, Curitiba, PR, Brasil.henke@ufpr.br \\ ${ }^{2}$ Instituto de Tecnologia Para o Desenvolvimento - LACTEC, Curitiba, PR, Brasil
}

\begin{abstract}
Resumo
A ferrita delta é considerada uma fase indesejável na microestrutura dos aços inoxidáveis martensíticos haja vista a mesma poder influenciar no desempenho da resistência à fadiga, tenacidade e corrosão sob-tensão. Sendo assim, o objetivo deste trabalho foi investigar o efeito da soldagem plasma pulsada sobre a distribuição e quantidade de ferrita delta em um aço inoxidável supermartensítico. Para tal foram obtidos cordões por meio de fusão superficial sobre uma amostra de aço inoxidável supermartensítico de alta liga utilizando corrente pulsada e convencional. Em seguida foi efetuada a caracterização microestrutural, em especial da ferrita delta, via análises metalográficas por meio de microscopia óptica e eletrônica de varredura. Os experimentos revelaram que, para o mesmo aporte térmico, a pulsação de corrente promoveu a formação de ferrita delta na forma de bandas ao longo do cordão de solda e redução significativa desta fase na ZTA quando comparada à soldagem convencional.
\end{abstract}

Palavras-chave: Ferrita delt, Supermartensítico, Soldagem pulsada.

Abstract: The objective of this study was to investigate the effect of pulsed plasma welding on the distribution and amount of delta ferrite which is considered an undesirable phase in a supermartensitic stainless steel. For such weld beads have been obtained by melting the surface of a sample of a high-alloy supermartensitic stainless steel using pulsed and conventional current. Microstructural characterization, especially of delta ferrite, was performed by metallographic analysis by means of optical microscopy and scanning electron microscopy. The experiments showed that for the same heat input, pulsed current promoted the formation of delta ferrite in the form of bands along the weld bead and caused a significant reduction of this phase in HAZ as compared to conventional welding.

Key-words: Delta ferrite, Supermartensitic, Pulsed welding.

\section{Introdução}

Os aços inoxidáveis martensíticos de baixo carbono, divididos em martensíticos macios e supermartensíticos tem sido utilizados em diferentes áreas da engenharia dentre estas como equipamentos de centrais hidrelétricas e em tubulações empregadas na produção de petróleo. O uso de tais aços se deve à necessidade de aliar resistência mecânica, resistência à corrosão e soldabilidade.

Apesar da boa soldabilidade destes aços em comparação aos martensíticos convencionais, tratamentos térmicos após a soldagem são normalmente requeridos de forma a minimizar os níveis de tensão residual e ainda garantir propriedades como tenacidade e resistência à corrosão sob-tensão [1,2]. Em função de tais tratamentos nem sempre possíveis de serem realizados em

(Recebido em 10/07/2012; Texto final em 14/08/2012). campo, procedimentos especiais de soldagem são necessários de forma a minimizar os níveis de tensão residual junto às regiões soldadas. Dentre estes, a soldagem com corrente pulsada. Esta técnica foi introduzida nos anos 60 como variante do processo com corrente constante e segundo a literatura resulta, dentre outras vantagens, em menor nível de tensão residual e refino da granulação da solda quando comparada ao processo convencional.

Com relação à microestrutura de tais aços, a mesma é constituída basicamente da fase martensítica e teores residuais de austenita, a qual promove o aumento da tenacidade. Após a soldagem a austenita retida é eliminada, vindo a ser substituída pela fase deletéria de ferrita delta $[3,4]$.

$\mathrm{O}$ efeito da ferrita delta na resistência ao impacto dos aços inoxidáveis martensíticos é ainda um assunto controverso. No entanto, Carrouge [3] verificou que a presença da ferrita delta interfere na resistência ao impacto aumentando a temperatura de transição dúctil-frágil (TTDF) de $-98{ }^{\circ} \mathrm{C}$ na condição de martensita (fresh) para $-46^{\circ} \mathrm{C}$ na condição contendo martensita mais $14 \%$ de ferrita delta. 
Wang et al [5] encontraram variações de resultado Charpy na faixa da TTDF de um aço inoxidável martensitico macio tipo CA6NM de $215 \mathrm{~J}$ para $103 \mathrm{~J}$ em aços contendo $0 \%$ e 7,8 \% de ferrita delta respectivamente. Estes autores afirmam ainda que em função da baixa resistência mecânica e ao cisalhamento da ferrita delta, ocorre a formação de trincas dúcteis no interior desta fase as quais "engatilham" a formação de fratura frágil na matriz de martensita revenida.

Com relação à influência da ferrita delta na resistência à fadiga, a literatura é escassa. Rho et al [6], ao submeterem um aço inoxidável austenítico AISI 304L ao ensaio de fadiga de baixo ciclo, verificaram que a presença desta fase reduz a resistência à fadiga do material haja vista a mesma propiciar o início da fratura na interface com a matriz.

Sanches-Cabrera et al [7] verificaram que a presença de ferrita delta na ZTA de um aço inoxidável foi a responsável pela baixa resistência à propagação de trincas por fadiga. Tal desempenho, segundo estes autores, estaria relacionado à susceptibilidade desta fase sofrer fragilização por hidrogênio.

Segundo Ladanova et al [8] a presença de ferrita delta permite a precipitação de carbonetos em seu interior devido à maior difusividade do carbono nesta fase em relação à austenita tornando o aço susceptível à corrosão sob-tensão. Conforme estes autores, estes aços tornam-se imunes a este fenômeno quando da presença de titânio. A ocorrência de corrosão sob-tensão na ZTA dos aços supermartensíticos envolvendo precipitação de carbonetos e ferrita delta também é citada por Turnbull e Nimo [9].

A quantidade de ferrita delta no interior da solda e ZTA está associada às condições de soldagem impostas haja vista a formação da mesma ser influenciada pelas taxas de resfriamento no interior do material. Sendo assim, o objetivo deste trabalho foi avaliar a microestrutura em especial a distribuição da ferrita delta resultante da soldagem plasma utilizando pulsação de corrente em comparação com a soldagem plasma convencional.

\section{Materiais e Métodos}

A seguir é descrita a metodologia utilizada no estudo comparativo entre o efeito da soldagem com corrente pulsada e convencional envolvendo um aço inoxidável supermartensítico (AISM).

Inicialmente é apresentado como foram obidos os cordões de solda e em seguida as análises voltadas na caracterização da ferrita delta.

\subsection{Obtenção dos cordões de solda}

Foram obtidos cinco cordões de solda, por meio de fusão (soldagem autógena) sobre a superfície de uma placa obtida por laminação e usinada medindo 200 × 100 × 20 mm de um AISM no estado temperado e revenido. A fusão do material visou simular tratamento superficial de endurecimento buscando melhorar propriedades como, por exemplo, resistência à cavitação. A Tabela 3.1 apresenta a composição química do material base utilizado.

As condições de soldagem adotadas para obtenção dos cordões são apresentadas na Tabela 2. A soldagem foi realizada com corrente contínua e polaridade direta (CC-). Demais parâmetros foram baseados em testes preliminares de forma a obter maior estabilidade de arco e qualidade de cordão.

A obtenção dos cordões foi realizada de forma automatizada utilizando-se uma fonte de soldagem multiprocesso IMC450 e uma tocha plasma refrigerada marca Thermal Dynamics modelo 300, acoplada a um sistema de deslocamento marca Bug-O. A velocidade de deslocamento da tocha plasma foi de $130 \mathrm{~mm} /$

Tabela 1. Composição química do material base utilizado para obtenção dos cordões ( \%p).

\begin{tabular}{|c|c|c|c|c|c|c|c|c|c|c|c|}
\hline $\mathrm{C}$ & $\mathrm{Si}$ & $\mathrm{Mn}$ & $\mathrm{Cr}$ & $\mathrm{Ni}$ & $\mathrm{Mo}$ & $\mathrm{Cu}$ & $\mathrm{V}$ & $\mathrm{Ti}$ & $\mathrm{Nb}$ & $\mathrm{P}$ & $\mathrm{S}$ \\
\hline 0,012 & 0,28 & 0,35 & 12,40 & 5,76 & 2,30 & 0,05 & 0,038 & 0,12 & $<0,01$ & 0,017 & 0,001 \\
\hline
\end{tabular}

Tabela 2. Parâmetros de soldagem utilizados para obtenção dos cordões por meio de fusão com plasma.

\begin{tabular}{|c|c|c|c|c|c|c|c|}
\hline Cordão - Condição & $I p(\mathrm{~A})$ & $I b(\mathrm{~A})$ & $\operatorname{Im}(\mathrm{A})$ & $T p(\mathrm{~s})$ & $T b(\mathrm{~s})$ & Tensão $(\mathrm{V})$ & Frequência $\mathrm{Hz}$ \\
\hline 1 - Convencional & - & - & 140 & - & - & 23 & - \\
\hline 2 - Pulsado A & 200 & 80 & 140 & 0,1 & 0,1 & 21 a 25 & 5 \\
\hline 3 - Pulsado B & 200 & 80 & 140 & 0,5 & 0,5 & 21 a 25 & 1 \\
\hline 4 - Pulsado C & 220 & 60 & 140 & 0,1 & 0,1 & 21 a 25 & 5 \\
\hline 5 - Pulsado D & 220 & 60 & 140 & 0,5 & 0,5 & 21 a 25 & 1 \\
\hline
\end{tabular}

$I p$, corrente de pico; Ib, corrente de base; Im, corrente média; $T p$, tempo de pico; $T b$, tempo de base

Tabela 3. Formulação do reativo metalográfico utilizado e procedimento de revelação da ferrita-delta [10].

\begin{tabular}{|c|c|}
\hline Formulação & Procedimento \\
\hline $20 \mathrm{ml} \mathrm{H}_{2} \mathrm{SO}_{4}$ & Ataque eletrolítico a $4 \mathrm{v}$ por \\
$0.01 \mathrm{~g} \mathrm{NH}_{4} \mathrm{CNS}$ & $20 \mathrm{~s}$. \\
$80 \mathrm{ml} \mathrm{H}_{2} \mathrm{O}$ & \\
\hline
\end{tabular}


min. Como gás de plasma e de proteção foi utilizado argônio nas vazões de 2.0 e $11 \mathrm{l} / \mathrm{min}$ respectivamente. Um eletrodo de tungstênio-toriado tipo EWTh-2 foi utilizado com recuo de 0,8 $\mathrm{mm}$ do bocal da tocha. A distância bocal-peça foi de $10 \mathrm{~mm}$.

\subsection{Caracterização microestrutural}

Após a realização dos cordões foram obtidos corpos-deprova metalográficos de forma a possibilitar a visualização da microestrutura desenvolvida ao longo das seções longitudinal e superior dos mesmos.

A obtenção da microestrutura foi realizada visando a revelação preferencial da ferrita delta. A formulação do reativo metalográfico utilizado bem como o procedimento de revelação encontram-se na Tabela 3.

Após a revelação foi efetuada a quantificação da ferrita delta na ZTA dos cordões por meio de software de análise de imagens analySIS 2.1 XL-PROF instalado junto ao microscópio eletrônico de varredura marca Philips modelo XL 30. Para tal foram obtidas três imagens em locais de interesse e em seguida efetuadas as quantificações por meio da "binarização" da imagem com três níveis de intensidade.

\section{Resultados e Discussão}

A Figura 1 revela aspectos macrográficos dos cordões obtidos por meio da fusão do metal base utilizando processo plasma com corrente convencional e pulsada depois de revelados com ataque específico para identificação de ferrita delta.

O cordão obtido por meio de corrente convencional, não pulsada, apresentou uma distribuição da ferrita delta homogênea ao longo de toda a região fundida (pontos claros na zona fundida da Figura 1a).

Para os cordões obtidos com corrente pulsada de 1 e $5 \mathrm{~Hz}$, (Figuras 1b e 1c) as análises revelaram a formação de bandas alternadas com e sem ferrita delta sendo o espaçamento destas bem como a largura das mesmas relacionados à frequência de pulsação, ou seja, quanto maior a frequência, menor o espaçamento e menor a largura das bandas.

A formação de tal bandeamento nos cordões com pulsação de corrente apresenta duas hipóteses.

A primeira estaria relacionada ao efeito promovido pelo reaquecimento do cordão solidificado pelos pulsos subsequentes. A origem de regiões sem ferrita delta seria a dissolução da mesma enquanto que nas regiões onde as temperaturas foram superiores à temperatura Ac4 ocorreria a precipitação e a manutenção desta fase durante o resfriamento. Quanto à possibilidade de dissolução da ferrita delta, a mesma é relatada por Carrouge [10] e Kou [11] sendo esta identificada em AISM e austenítico AISI 309 (estrutura mista de austenita e ferrita delta) respectivamente, os quais sofreram reaquecimento pelos passes subsequentes.

Aliada a esta hipótese, a morfologia da microestrutura constatada nas bandas contendo ferrita delta se assemelha à da formada na ZTA de alta temperatura (ZTA-AT) identificada no

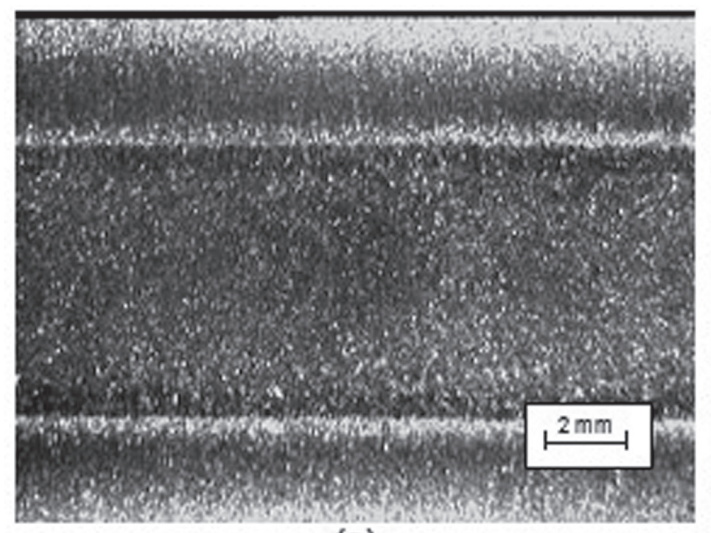

(a)

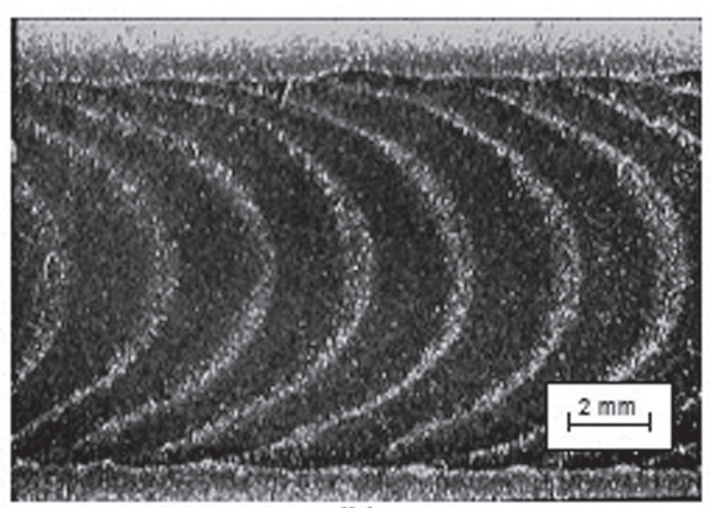

(b)

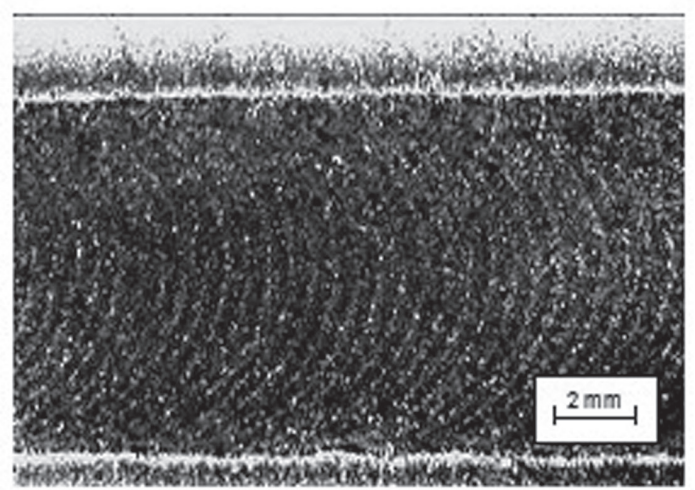

(c)

Figura 1. Aspectos macrográficos dos cordões obtidos com corrente convencional (a) e pulsada a $1 \mathrm{~Hz}$ (b) e $5 \mathrm{~Hz}$ (c). Áreas brancas no interior dos cordões revelam a presença de ferrita delta. 
trabalho de Carrouge et al [10]. Segundo estes autores, acima da temperatura Ac4 do diagrama Fe-Cr a austenita começa a se transformar em ferrita delta (ZTA-DF) e a reação é completada acima da temperatura Ac5. Uma vez que a ferrita delta é totalmente formada ocorre também elevado crescimento de grão (ZTA-GG). Durante o resfriamento, a ferrita delta decompõe-se em austenita alotriomórfica, intragranular e de Widmanstätten. Abaixo de Ms a austenita transforma-se em martensita. Elementos estabilizadores de ferrita ( $\mathrm{Cr}$ e Mo) tendem após resfriamento a partir destas temperaturas onde esta fase se faz presente estabilizarem maior quantidade de ferrita delta na ZTA quanto maior o teor destes elementos. Tal morfologia é apresentada na Figura 2 sendo que a banda contendo ferrita delta é constituída de uma região de grãos grosseiros (ZTA-GG) e outra com granulação fina proveniente da zona de dupla fase (ZTA-DF) existente no digrama Fe-Cr.

A segunda hipótese para a formação de bandas com e sem ferrita delta estaria relacionada à segregação de soluto decorrente de variações na taxa de crescimento do sólido $R$ resultantes de oscilações térmicas [11]. Segundo Kou [11] quando a taxa R é aumentada subitamente, uma quantidade extra de soluto é rejeitada para o líquido na interface líquido-sólido promovendo o aumento da concentração de soluto nesta região. Como resultado, o material solidifica-se com uma concentração de soluto superior ao da anterior à variação na taxa de solidificação. Destacase que uma redução da taxa $\mathrm{R}$ resulta no efeito contrário, ou seja, uma menor quantidade de soluto é rejeitada para o líquido e consequentemente uma menor concentração é constatada anterior à variação. Fatores como pulsação de arco, liberação de calor latente de fusão, instabilidades no arco elétrico, variações de fluxo do gás de proteção e turbulências provocadas pelo campo magnético seriam as responsáveis pela flutuação na frente de solidificação. Segundo Svensson [14] tal variação de soluto pode ser decorrente de uma transição do modo de solidificação de planar para dendrítico. Durante o crescimento planar há o acúmulo de soluto na frente de solidificação enquanto que para um modo de solidificação mai acelerado, um decréscimo.

Quando efetuadas análises de composição via MEV/EDS sobre as regiões contendo ferrita delta e fora desta não foram constatadas variações de composição (Tabela 4). Provavelmente a técnica de MEV/EDS não seja a mais adequada para tal caracterização podendo se dizer o mesmo em relação à obtenção da composição química do material base.

Infere-se, com base nas informações apresentadas no item 1 , que a formação de tais bandas de ferrita delta possa vir a comprometer aspectos relativos à resistência à corrosão, tenacidade e fadiga. Com relação a esta última propriedade, Henke [13] realizou ensaios de fadiga por flexão em quatro pontos em corpos de prova contendo bandeamento de ferrita delta na condição como soldada. Nestes corpos de prova a nucleação das trincas ocorria na ZTA, especificamente sobre inclusões não metálicas, minimizando em parte o comprometimento da presença do bandeamento. Segundo este autor, ensaios de fadiga em corpos de prova contendo apenas a zona fundida bandeada devem ser ensaiados em trabalhos futuros a fim de melhor avaliar a influência desta com relação a esta e/ou outras propriedades.

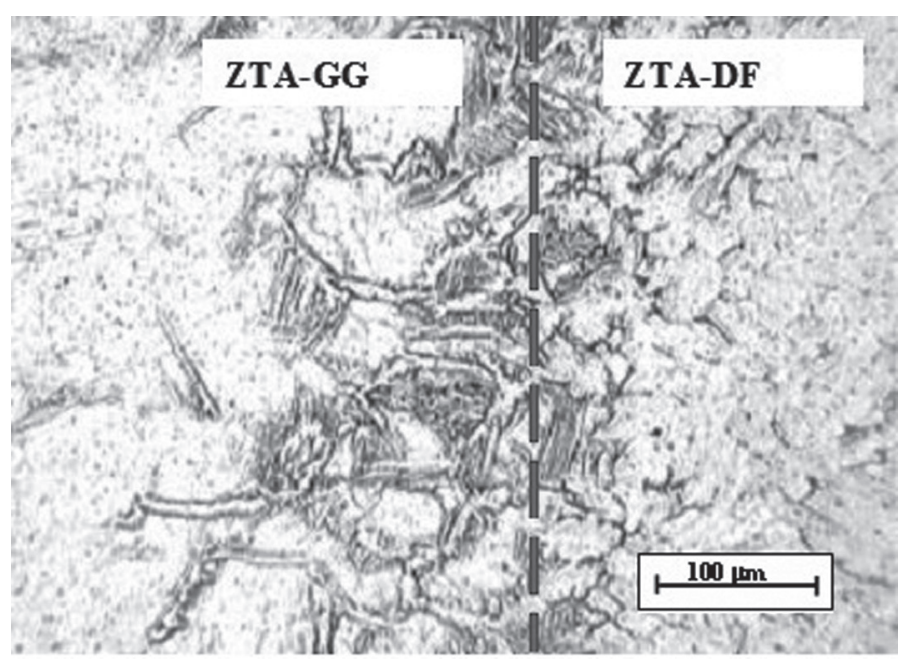

Figura 2. Micrografia obtida sobre banda de ferrita delta apresentando morfologia típica de ZTA-AT contendo granulação grosseira (ZTA-GG) e de dupla fase (ZTA-DF). A ferrita delta é representada pelas linhas escuras na micrografia.

Quando observadas as microestruturas da zona termicamente afetada, foi constatada uma maior quantidade de ferrita delta para o cordão na condição convencional em relação aos cordões obtidos com pulsação de corrente (Figuras 3 a 5). Na figura 6 são apresentadas as quantidades volumétricas de ferrita delta para cada um dos cordões. O valor máximo obtido foi de 18 $\pm 1 \%$ para a condição convencional e o mínimo foi de $7 \pm 1 \%$ para cordão 5 - Pulsado D. Carrouge [10] utilizando tocha TIG no modo convencional encontrou valores de $27 \pm 5 \%$ de ferrita delta na ZTA de um AISM, sendo tal valor considerado elevado por este autor.

A justificativa para tal constatação ainda é de natureza complexa exigindo estudos futuros. No entanto deduz-se que os menores valores de ferrita delta revelados para o modo pulsado seriam decorrentes do menor tempo de permanência acima da temperatura Ac4 bem como de uma possível ação de dissolução desta fase proveniente da pulsação. Tal constatação é mais evidente quanto menor a frequência utilizada e quanto maior a diferença entre $I p$ e $I b$. Aliado a isto, segundo Yousefieh et al [12] pelo fato da energia necessária para fundir o material ser fornecida durante a corrente de pico em breve intervalos de tempo, isto permite que o calor se dissipe para o interior do material originando uma ZTA mais estreita. Além disto, durante a pulsação, os pulsos subsequentes encontram o metal

Tabela 4. Resultados de composição obtidos via EDS (\%p) sobre regiões de bandas com e sem ferrita delta.

\begin{tabular}{|ccccc|}
\hline Região & $\mathrm{Cr}$ & $\mathrm{Ni}$ & $\mathrm{Mo}$ & $\mathrm{Si}$ \\
\hline Banda com ferrita delta & $11,1 \pm 0,1$ & $5,5 \pm 0,3$ & $1,6 \pm 0,1$ & $0,6 \pm 0,1$ \\
\hline Banda sem ferrita delta & $11,1 \pm 0,1$ & $5,7 \pm 0,1$ & $1,6 \pm 0,1$ & $0,6 \pm 0,1$ \\
\hline
\end{tabular}




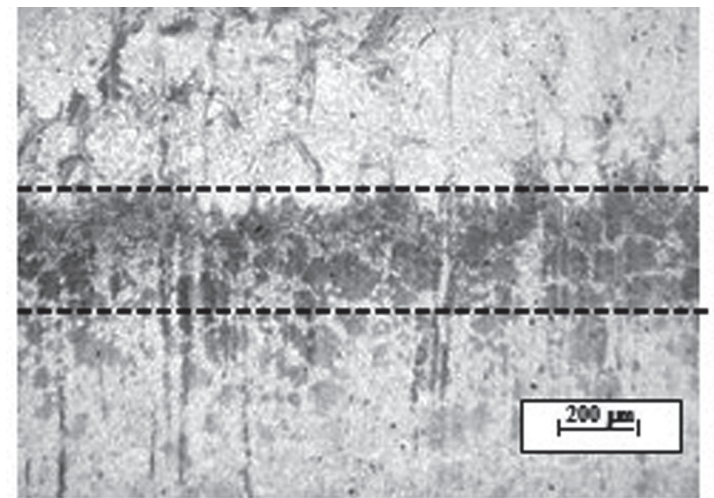

(a)

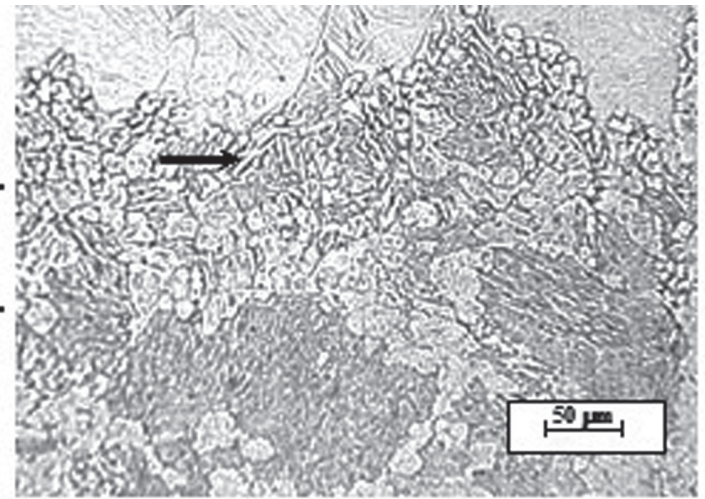

(b)

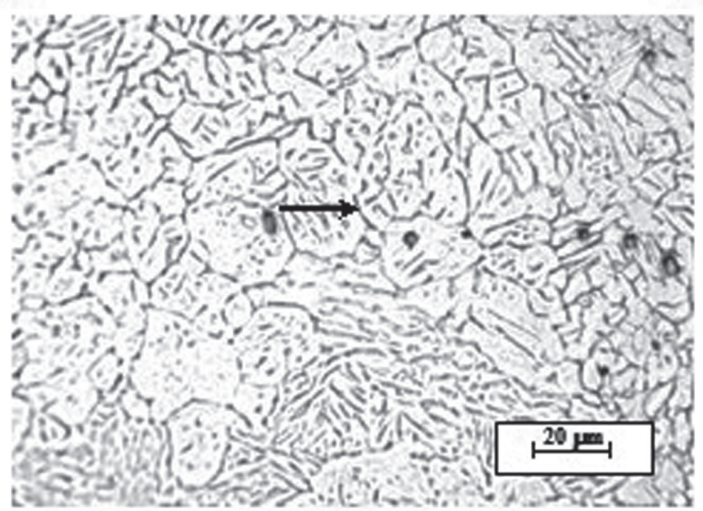

(c)

Figura 3. Microestruturas obtidas com diferentes ampliações sobre a ZTA do Cordão 1 - Condição Convencional - Im 140 A destacando a presença de ferrita delta (áreas escuras entre as linhas tracejadas em (a) e setas em (b) e (c)).

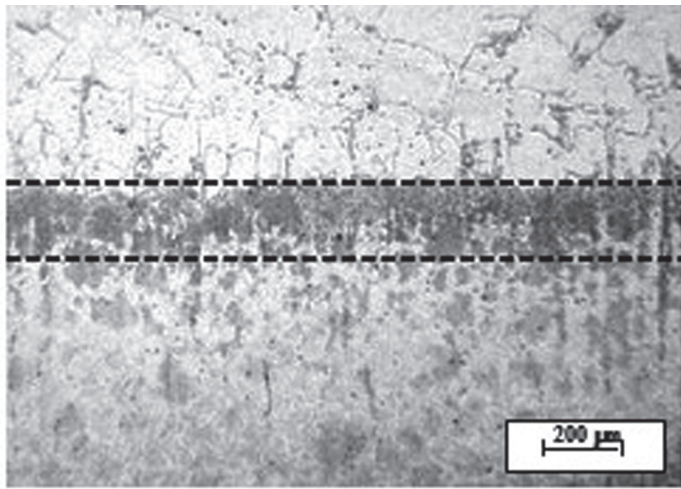

(a)

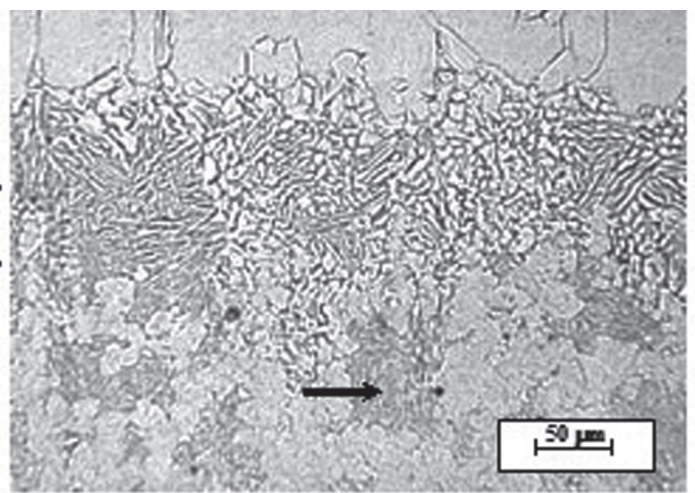

(b)

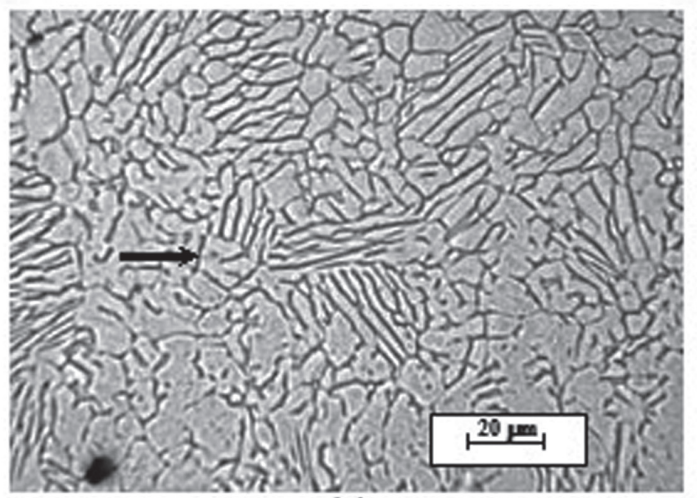

(c)

Figura 4. Microestruturas obtidas sobre a ZTA do Cordão 4 - Condição Pulsado C Tp e Tb 0,1 s; Ip 220 A, Ib 60 A destacando a presença de ferrita delta (áreas escuras entre as linhas tracejadas em (a) e setas em (b) e (c)). 


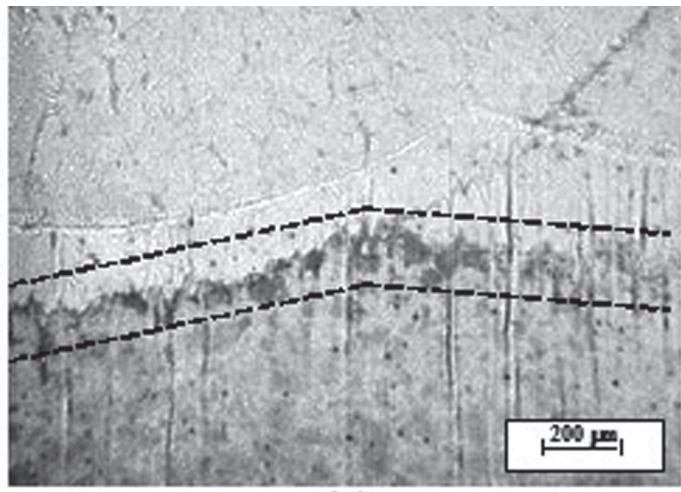

(a)

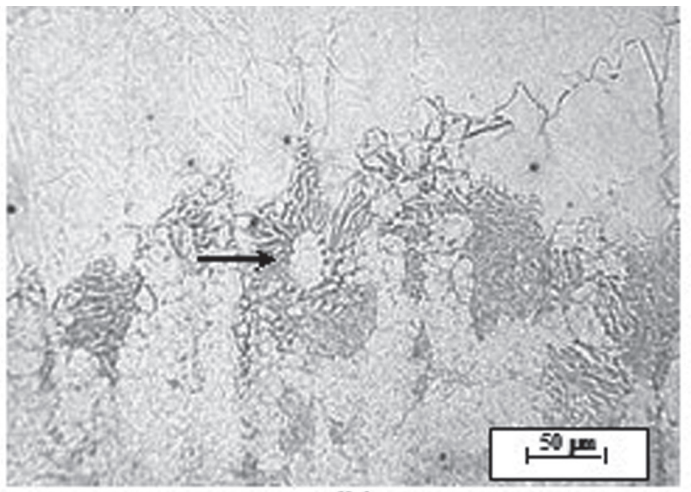

(b)

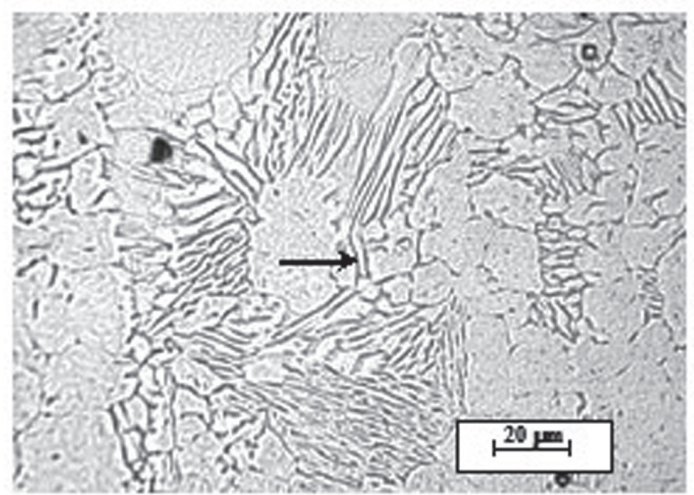

(c)

Figura 5. Microestruturas obtidas sobre a ZTA do Cordão 5 - Condição Pulsado D Tp e Tb 0,5 s; Ip 220 A, Ib 60 A destacando a presença de ferrita delta (áreas escuras entre as linhas tracejadas em (a) e setas em (b) e (c)).

pré-aquecido pelos pulsos anteriores promovendo um menor superesfriamento e consequentemente uma maior dissolução da ferrita delta.

Infere-se que a obtenção de menor quantidade de ferrita delta por meio da pulsação de corrente seria uma forma de minimizar a ação deletéria desta fase, como, por exemplo, segundo Turnbull e Nimo [9] na resistência à corrosão sob-tensão na ZTA dos AISM.

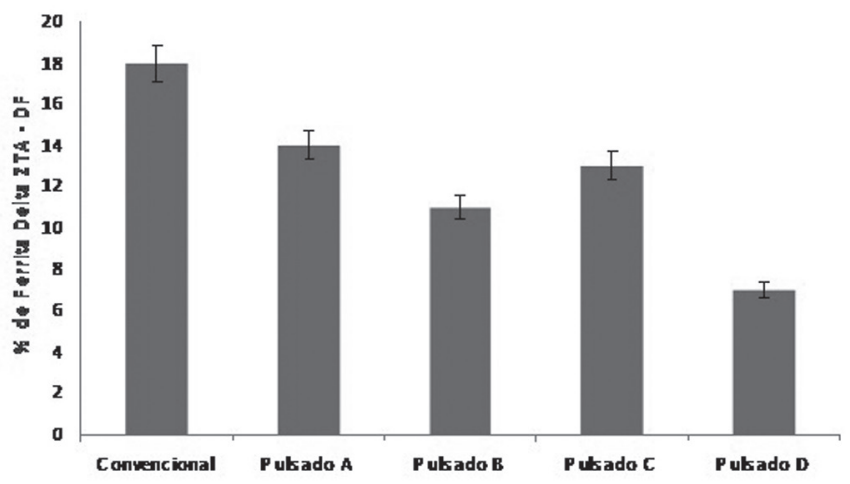

Figura 6. Porcentagem de ferrita delta na ZTA em função do procedimento de soldagem utilizado.

\section{Conclusões}

O trabalho apresentado teve como objetivo comparar o efeito da soldagem plasma pulsada e convencional sobre a formação de ferrita delta de um aço inoxidável supermartensítico.

Com base no estudo realizado é possível destacar o seguinte:

- Foi verificado que o processo de soldagem utilizando corrente pulsada promove na zona fundida a formação de bandas de ferrita delta a qual é considerada uma fase potencialmente deletéria para tais aços. Tal efeito é mais acentuado quanto menor a frequência de pulsação.

- Na ZTA do aço inoxidável supermartensítico estudado foi constatada uma redução nos porcentuais ferrita delta de 18 para $7 \%$ quando do uso da corrente pulsada frente à convencional. Infere-se que tal redução seria decorrente do menor tempo de permanência acima da temperatura Ac4 bem como de uma possível ação de dissolução desta fase proveniente da pulsação.

\section{Agradecimentos}

Os autores agradecem à empresa Villares Metal's pelo fornecimento de amostras do aço inoxidável supermartensítico. 


\section{Referências Bibliográficas}

[1] RAMIREZ J. E., Weldability evaluation of supermartensitic stainless pipe steels Weld. J., USA, v. 86, May 2007.

[2] BILMES, P., et al.;Toughness and microstructure of 13Cr4NiMo high-strength steel welds; Journal of Materials Engineering and Perfomance, Vol 9(6), p 609-615, Dec, 2000.

[3] CARROUGE D.; BHADESHIA H. K. D. H.; WOOLLIN P.; Effect of $\delta$-ferrite on impact properties of supermartensitic stainless steel heat affected zones, Science and Technology of Welding and Joining Vol. 9 No. 5, 2004.

[4] DAS, C. R. et al.; Effect of minor change in composition on toughness of weldmetal for repair of turbine blades made of martensitic stainless steel, Science and Technology of Welding and Joining, Vol. 13, Nr. 2159 -166, 2008.

[5] WANG P., LU S. P., XIAO N. M., LI D. Z., LI Y. Y., Effect of delta ferrite on impact properties of low carbon $13 \mathrm{Cr}-4 \mathrm{Ni}$ martensitic stainless steel, Mat. Science \& Engineering A, accepted manuscript, doi:10.106/j.msea.2010.01.085

[6] RHO S. B., HONG H. U., NAM S.W., The effect of $\delta$-ferrite on fatigue cracks in $304 \mathrm{~L}$ steels. International Journal of Fatigue 22, 2000, p683-690.

[7] SANCHES-CABRERA V.M., RUBIO-GONZALEZ C., RUÍZ-VILELA J.I.,RAMIREZ-BALTAZAR C., Effect of preheating temperature and filler metal type on the microstructure, fracture toughness and fatigue crack growth of stainless steel welded joints. Materials Science and Engineering, A 452-453, 2007, p235-243.

[8] LAdANOVA, E. SOlBerG, J.K., ROGNE, T. Carbide precipitation in HAZ of multipass welds in titaniun containing and titaniun free supermartensitic satinless steels Part 1 proposed precipitation mechanisms. Corrosion Engineering, Science and Technology Vol. 41, p143-151, 2006.

[9] TURNBUlL A., NIMO B., Stress corrosion testing of welded supermartensitic stainless steels for oil and gas pipelines. Corrosion Engineering, Science and Technology, 2005, vol. 40 no. 2 p103-109.

[10] D. Carrouge, H.K.D.H. Bhadeshia and P. Woollin. Microstructural change in high temperature heat-affected zone of low carbon weldable $13 \% \mathrm{Crm}$ artensitic stainless steels. Proceedings of the stainless steel world conference. p61-67, 2002.

[11] KOU, S., Welding metallurgy. Book, John Wiley \& Sons. 2003.

[12] YOUSEFIEH M., SHAMANIAN M., SAATCHI A.; Optimization of the pulsed current gas tungsten arc welding (PCGTAW) parameters for corrosion resistance of super duplex stainless steel (UNS S32760) welds using the Taguchi method. Journal of Alloys and Compounds 509 (2011) 782-788.

[13] HENKE, S. L.; Efeito da soldagem plasma pulsada na microestrutura e resistência à fadiga de um aço inoxidável supermartensítico. Tese. UFPR-PGMEC, 2010.

[14] SWENSSON, L-E.; Control of microstructures and properties in steel arc welds. Book Esab Group, CRC Press.1994. 